\title{
Estudo exploratório sobre a causalidade psíquica em paciente com queixa de zumbido crônico
}

\author{
Adriane Maria Moro Mendes ${ }^{1}$ \\ Bruna de Franceschi Schirmer ${ }^{2}$ \\ Maria Tereza Andreola ${ }^{3}$
}

\begin{abstract}
Resumo: A patologia, tanto em aspecto psíquico, quanto somático é um reflexo da vida do indivíduo; é a manifestação externa da sua vida interior, que na maioria das vezes são contraditórias. Para que ocorra a cura de determinados sintomas e doenças expressados de modo físico é imprescindível fazer a busca dos fatores etiológicos também na esfera psíquica. Objetivo: Descrever um caso clínico, com queixa de zumbido crônico, sem nenhuma alteração orgânica. Através de anamnese linguística, biografia histórica, Teste dos seis desenhos (T6D) e análise onírica buscou-se verificar uma correspondência entre sintoma e atividade psíquica. Metodologia: O trabalho foi composto por quatro encontros, estruturados do seguinte modo: 1) Anamnese Linguística e biografia histórica e Audiometria Tonal Liminar; 2) conversa para o aprofundando da Anamnese Linguística histórica e relato de um sonho; 3) relato de mais um sonho; 4) realização do T6D. Tanto os sonhos quanto o teste dos Seis Desenhos (T6D) foram analisados segundo a metodologia da escola ontopsicológica para análise das imagens: 1) natureza causal do símbolo. 2) Efetividade funcional para o sujeito. 3) Critério semântico. Resultados: os achados sugerem, Tendência a Autossabotagem, indicando frustração, estagnação e regressão. Conclusão: acredita-se que o zumbido possa ter ligação com as manifestações psíquicas demostradas, pois quando o impulso de energia vital não possui mais função de ida e volta, o sujeito vivencia o mal. Principalmente, nos casos em que o sujeito deveria e tinha possibilidade de agir, não o faz.
\end{abstract}

Palavras-chave: Ontopsicologia; Psicossomática; Inconsciente; Zumbido.

\footnotetext{
${ }^{1}$ Doutorado em Engenharia e Gestão do Conhecimento, UFSC, Graduação em Farmácia e Bioquímica pela UFSC, e em Psicologia pela UFSC, Especialização em Ontopsicoloogia pela UNICEUB. Especialização em Psicologia com abordagem em Ontopsicologia pela Universidade Estatal de São Petersburgo, Rússia, coaching.assessoria@gmail.com.

2 Mestre em Distúrbios da Comunicação Humana, Fonoaudióloga, UFSM. Especialista em Gestão do Paradigma Ontopsicológico, AMF, schirmer.bf@gmail.com.

${ }^{3}$ Mestra em Ciências da Saúde pela UFSC, Graduação em Psicologia pela UPF, Especialização em Gestão de Negócios e Intuição pela AMF, RS, Especialização Profissional em Psicologia com abordagem em Ontopsicologia pela Universidade Estatal de São Petesburgo, Rússia, Especialização em Psicologia para o Magistério Superior pela UNIVALI, Especialização em Ontopsicologia pelo UniCEUB, Especialização em Administração dos Serviços de Saúde pela UNIP.
} 


\title{
Exploratory Study on Psychic Causality in a Patient Complaining of Chronic Tinnitus
}

\begin{abstract}
Pathology, both in psychic and somatic aspects, It is a reflection of the individual's life; is the outward manifestation of their inner life, which in most cases is contradictory. For the cure of certain symptoms and diseases expressed in a physical way, it is essential to search for etiological factors in the psychic sphere as well. Objective: to describe a clinical case, with a complaint of chronic tinnitus, without any organic changes. Through linguistic anamnesis, historical biography, Test of the six drawings (T6D) and dream analysis, we tried to verify a correspondence between symptom and psychic activity. Methodology: the study was composed of four meetings, structured as follows: 1) Linguistic Anamnesis and historical biography and Tonal Limit Audiometry; 2) talk to the deepening of the Historical Linguistic Anamnesis and report of a dream; 3) a report of another dream; 4) realization of T6D. Both the dreams and the test of the Six Drawings (T6D) were analyzed according to the methodology of the Ontopsychological school to analyze the images: 1) causal nature of the symbol. 2) Functional effectiveness for the subject. 3) Semantic criterion. Results: the findings suggest, Self-sabotage tendency, indicating frustration, stagnation and regression. Conclusion: it is believed that tinnitus may have a connection with the demonstrated psychic manifestations, because when the vital energy impulse no longer has a back and forth function, the subject experiences evil. Primarily, in cases where the subject should and could act, he does not.
\end{abstract}

Keywords: Ontopsychology; Psychosomatic; Unconscious; Tinnitus.

\section{Estudio Exploratorio De Causalidad Psíquica En Paciente Con Queja De Zumbido Crónico}

Resumen: La patología, tanto en el aspecto psíquico como somático, es un reflejo de la vida del individuo; es la manifestación exterior de tu vida interior, que a menudo es contradictoria. Para que ocurra la curación de ciertos síntomas y enfermedades expresadas de forma física, es fundamental buscar los factores etiológicos también en la esfera psíquica. Objetivo: Describir un caso clínico, que se queja de acúfenos crónicos, sin cambios orgánicos. Através de la anamnesis lingüística, la biografía histórica, el Test de los seis dibujos (T6D) y el análisis del sueño, buscamos verificar una correspondencia entre síntoma y actividad psíquica. Metodología: El trabajo estuvo compuesto por cuatro encuentros, estructurados de la siguiente manera: 1) Anamnesis lingüística y biografía histórica y audiometría tonal pura; 2) conversación para profundizar en la anamnesis lingüística histórica y relato de un sueño; 3 ) informe de otro sueño; 4) realizar el T6D. Tanto los sueños como el test de los Seis Dibujos (T6D) fueron analizados según la metodología de la escuela ontopsicológica para el análisis de la imagen: 1) la causalidad del símbolo. 2) Eficacia funcional para el sujeto. 3) Criterios semánticos. Resultados: los hallazgos sugieren, Tendencia al Autosabotaje, indicando frustración, estancamiento y regresión. Conclusión: se cree que el tinnitus puede tener una conexión con las manifestaciones psíquicas mostradas, porque cuando el impulso de energía vital deja de tener una función de ida y vuelta, el sujeto experimenta el mal. Principalmente, en los casos en que el sujeto debería y pudo actuar, no lo hace.

Palabras clave: Ontopsicología; Psicosomática; Iconsciente; Acúfenos. 


\section{Introdução}

Os tempos atuais são norteados pelas grandes descobertas tecnológicas e avanços na ciência, no entanto, ainda existem lacunas no que diz respeito a ligação entre sintoma e causa. Como por exemplo, nos casos de zumbido crônico. Sintoma este, que em muitos casos acompanha o sujeito por longos anos de sua vida, pois muitas vezes não se consegue encontrar o real fator causal dificultando assim, o tratamento e intervenção adequados. Portanto, este trabalho trará um caso clínico de zumbido crônico em que se investiga o seu real fator causal.

Ontopsicologia é a ciência responsável “(...) pelos comportamentos psíquicos em primeira atualidade, não excluída a compreensão do ser; estudar psicologia segundo coordenadas do real, ou intencionalidade da ação-vida, ou ação-ser. Trata-se de partir do real fato antropológico e não da sua cultura ou de suas reflexões (...)" (MENEGHETTI, 2010, pg.19).

A ciência em questão tem como análise o evento homem em sua existência e historicidade. Questiona os formais, bem como, os processos que estruturam o homem no iso de natureza (MENEGHETTI, 2010). Através da práxis clínica, a Ontopsicologia tem autoridade no que diz respeito a compreensão e resolução da neurose, da esquizofrenia e da psicossomática.

Quando o indivíduo é saudável significa que existe um critério de boa conduta em relação a grande lei da vida (MENEGHETTI, 2010). Segundo Meneghetti (2005), a saúde decorre da livre fluidez de energia em referimentos múltiplos e convergência monística. No momento que um dos pontos do multíplice não tem mais função de ida e volta do impulso de energia ou vida, o sujeito vivencia o mal. No entanto, para que isso ocorra faz-se necessário uma linha de vitalidade do indivíduo que deveria e tinha possibilidade de agir, mas não o faz.

Psicossomática é o termo utilizado para denominar a unidade hilemórfica (matéria = corpo, forma = alma) a qual é a unidade de ação homem. Que em suma significa alteração orgânica funcional ou de estrutura com causa, exclusiva, psíquica (MENEGHETTI, 2012a). 
A doença (aspecto psíquico ou somático) é uma linguagem do vivido amplo do homem; é a criação externa de suas vivências interiores, em sua maioria conflitantes. Não é possível curar determinados mal-estares que se expressam de modo físico, sem buscar a etiologia também no âmbito psicológico (MENEGHETTI, 2010). A patologia afrontada neste trabalho é o zumbido. De acordo com a literatura o zumbido pode ser explicado como uma alucinação auditiva, isto é, uma sensação auditiva, que não está relacionada a nenhuma fonte sonora externa. (SAHLEY \& NODAR, 2001). Este sintoma é um dos mais intrigantes da otorrinolaringologia, porém a complexidade de sua fisiopatologia, bem como a sua subjetividade enfraquecem o interesse dos profissionais desta área (SANCHEZ et. al., 2005).

O zumbido é um sintoma que pode ser gerado por inúmeras afecções otológicas, metabólicas, neurológicas, cardiovasculares, farmacológicas, odontológicas e psicológicas, as quais, podem se manifestar de modo isolado ou concomitante (SANCHEZ, 2002); (SANCHEZ, 2003).

Este trabalho tem o objetivo de descrever um caso clínico, com queixa de zumbido crônico, sem nenhuma alteração orgânica. Através de anamnese linguística, biografia histórica, Teste dos seis desenhos (T6D) e análise onírica buscou-se verificar uma correspondência entre sintoma e atividade psíquica.

\section{Desenvolvimento Teórico e Aplicação Metodológica}

Este trabalho se trata de um estudo de caso clínico, de paciente com queixa de zumbido constante.

O trabalho em questão foi composto por quatro encontros, sendo que os mesmos foram estruturados do seguinte modo:

- Primeiro Encontro: Anamnese Linguística e biografia histórica e Audiometria Tonal Liminar;

- Segundo encontro: conversa para o aprofundando da Anamnese Linguística histórica e relato de um sonho;

- Terceiro encontro: relato de mais um sonho;

- Quarto Encontro: realização do T6D.

Tanto os sonhos quanto o teste dos Seis Desenhos (T6D) foram analisados segundo a metodologia da Escola Ontopsicológica para análise das imagens: 1) natureza causal do 
símbolo. 2) Efetividade funcional para o sujeito. 3) Critério semântico (MENEGHETTI, 2010). Todos esses critérios são interligados com os quatro fatores-fonte da psicogênese do símbolo (realidade social, instintos, impressão recebida de semânticas compulsivas do externo, pulsões meta-históricas) e os quatro elementos que se consideram em qualquer processo de interpretação (ação em mutação, ambiente, pessoas, sentimentos).

A base para interpretação da simbologia foi o livro Prontuário Onírico (MENEGHETTI, 2012b).

Para análise do T6D de modo foram utilizadas sete categorias: 1) proporção entre o desenho e o espaço da folha (desenho da árvore); 2) posição do desenho na folha (desenho da árvore); 3) proporção entre o tronco, copa e base de sustentação no desenho da árvore (presença da terra em contato com a base do tronco); 4) particulares que complementam o habitat (desenho da árvore); 5) hierarquia de importância de ação na situação existencial atual (análise do desenho da situação atual comparada com o desenho da árvore); 6) direção de valor da ambição existencial (análise do desenho da situação futura); 7) intenção de empenho para o crescimento (análise do desenho de situação atual comparada com o desenho de situação futura) (ANDREOLA, 2013).

Quanto a análise dinâmica subjetiva do T6D, utilizou-se critérios de classificação, sendo estes: Tendência de abertura à mudança em Autorrealização - a qual foi utilizada quando se atingiram cinco ou mais itens da análise, anteriormente citada. No caso das demais situações considerou-se Tendência a Autossabotagem. É importante salientar, que cinco dos sete critérios são determinantes, sendo estes: 3,4,5, 6 e 7. Os demais podem ser condicionantes ( 1 e 2) para a definição da dinâmica de personalidade atual do indivíduo (ANDREOLA, 2013).

Ressalta-se que a análise Onírica, foi realizada em conjunto pela autora do trabalho, suas Orientadora e Coorientadora, (ambas Ontopsicólogas) assim como a análise do Teste dos Seis Desenhos (T6D), o que assegura a confiabilidade da análise.

\section{APRESENTAÇÃO DO CASO}

\subsection{DESCRIÇÃO E ANÁLISE DO CASO}

O caso será apresentado através do relato dos encontros realizados com a paciente. 


\subsubsection{Primeiro Encontro - Anamnese}

M.C. 32 anos, gênero feminino, profissional da área da saúde. Relata que seu desenvolvimento infantil foi adequado, sem nenhum tipo de intercorrência. Tem um irmão cerca de um ano mais novo, seus pais se separaram quando ela tinha 12 para 13 anos. Refere que por volta de seus 09 anos uma mulher ligou para sua casa perguntado: "seu pai ou sua mãe estão em casa?" e ela disse: "não", deste modo, a mulher falou "avisa seu pai que a filha dele nasceu." Porém, mesmo ela achando que se tratava de um engano ela avisou sua mãe.

Mais tarde ela viria a saber que se tratava mesmo de seu pai e que logo ele sairia de casa para morar com essa nova família. M. referiu vivenciar algumas brigas significativas entre os pais até que eles de fato, se divorciassem.

Após o divórcio, ela morou com a mãe e o irmão até ir para a capital do seu estado para fazer faculdade. Neste período morou com seu irmão "de favor" na casa de sua tia paterna, o que não era uma situação agradável, principalmente pela invasão da tia em sua vida. Ela relatou ainda, que o pai mesmo tendo condições econômica, apresentava resistência em fornecer os subsídios financeiros necessários e a mãe por sua vez "jogava" os filhos contra o pai, parecendo por muitas vezes se incomodar com os próprios filhos por serem uma lembrança do ex-marido. M. mora sozinha e longe de sua família a mais ou menos 05 anos. Apresenta a queixa de zumbido contínuo já há muitos anos, não sabendo precisar quando começou, mas lembra que no período da faculdade já o possuía. Ela referiu que o sintoma piora com exposição ao estresse. Refere não apresentar problemas de saúde.

Inspeção Visual do Meato Acústico Externo: sem particularidades.

Audiometria Tonal Liminar: Dentro dos padrões de normalidade (LLOYD \& KAPLAN, 1978).

Foi possível perceber que a paciente é uma mulher com considerável força interior, mas que no seu modo de se mover e falar, demonstra certa fragilidade e em certos momentos se demonstra bastante sedutora.

\subsubsection{Segundo Encontro - Sonho 01}

Após uma conversa introdutória, a paciente relatou o seguinte sonho: "Eu lembro que assim eu estava não sei exatamente onde mas parecia um bairro lá em Salvador (BA) no centro de Salvador, o bairro do Campo Grande mas não sei exatamente o local e tinha, eu 
lembro que eu via meu irmão, e tinha algum tiroteio as pessoas gritando tá tendo tiro, tá tendo tiro e nisso eu comecei a sentir meus dentes se esfarelando e eu passava a língua, quanto mais eu passava a língua mais caia pedaço, parecia areia e aí depois alguém estava segurando minha mão, também não sei dizer quem e aí eu lembrei meu irmão e aí eu ia queria sair pra ir contra as pessoas para ir buscar meu irmão e de repente ele vinha com o nariz sangrando e eu disse: - Meu irmão mas o que que aconteceu? E ele não conseguia falar e eu só conseguia visualizar ele assim com o nariz sangrando e meus dentes caindo". Referiu sonhar bastante com dentes caindo, se esfarelando.

M. relembra sobre o período que morou em Salvador com sua tia, primos e irmão. Conta da ausência do pai e da dificuldade em se relacionar com a mãe. Ao final quando pergunto se ela está sentindo algo, se teria algo que ela queira me contar, além do que já foi dito, ela começa a chorar e relata que é bastante difícil falar sobre tudo isso, pois não são boas lembranças. Durante seu choro sinto grande tristeza.

\subsubsection{Terceiro Encontro - Sonho 02}

Após breve conversa para esclarecer aspectos da história pregressa da paciente, esta relata o seguinte sonho: "Eu estava no Crossfit, mas era um lugar parecendo um labirinto feito com contêineres e comecei a subir e eu tentava descer e não conseguia até que eu acordei. Depois peguei no sono novamente e sonhei que estava em uma lancha e ela ia para o alto mar muito rápido e balançava muito e eu deitada dentro dela tentando me cobrir para não me molhar e não cair no mar, até que ela voltou para a praia e eu descia apavorada".

\subsubsection{Quarto Encontro - Realização do T6D}

$\mathrm{Na}$ ocasião a paciente relatou não ter se recordado de nenhum sonho, mas referiu ter tido uma noite bastante agitada com vários despertares e referiu também ter brigado com sua mãe por telefone antes de dormir. Sugeriu que sua mãe fizesse terapia e ela se incomodou muito com a sugestão. 


\subsection{Discussão}

\subsubsection{Quanto a Atividade Onírica}

"O sonho é o espelho holístico da atividade orgânico-funcional do nosso existir" (MENEGHETTI, 2012c, p. 29).

A atividade onírica é o modo como o organismo se exercita nas suas múltiplas partes e funções. A consciência é um modo de reflexão, ou seja, uma maneira especular que é utilizada para mostrar certos comportamentos. Do contrário, a atividade onírica corresponde a um espelho completo do funcionamento do orgânico funcional.

O sonho, em mãos de inteligentes racionais, é um modo de revelação em relação a maneira de conduzir a existência. No sonho, as imagens ou símbolos, possuem uma precisa intencionalidade. A atividade Onírica é uma projeção das variáveis, bem como das alterações, funcionais e estruturais do organismo do homem. Ela reflete aquilo que na realidade já ocorreu, no que diz respeito a totalidade psíquica e somática. O sonho permite que se visualize o interior de uma ação.

Através da atividade onírica é possível, por exemplo, captar a causa, o modo e o objetivo de uma patologia, situação, de uma estratégia familiar, científica, econômica, política, social (MENEGHETTI, 2012c).

Em relação a doença de qualquer gênero, o sonho é muito pontual e revelador em relação a situação doentia ou perversa do indivíduo, pois é possível questioná-lo no ponto de perda se si mesmo (MENEGHETTI, 2010).

Deste modo, colhe-se o mal no seu modo de se expor, bem como na sua atividade de causa. A atividade onírica é uma passagem muito segura no que consente a análise. Utilizando-se todos os instrumentos de aprendizagem científico bem como, racional. A estrutura de análise do sonho é o modo mais seguro para se obter o diagnóstico preciso, do contrário quando se busca analisar por meio de sedimentação exposta, já se está atrasado (MENEGHETTI, 2012c).

Os símbolos em um sonho, devem ser lidos a partir da lógica funcional, exclusiva, do sonhador. Deve-se recuperar o código-base da natureza em sentido biológico, ultrapassando os estereótipos culturais e científicos. A atividade onírica vai utilizar qualquer símbolo, para mostrar se algo é saudável ou não para a identidade histórica do sonhador. 
A atividade onírica é muito precisa no que diz respeito ao valor do indivíduo. É muito clara na medida em que o Em Si ôntico pode existir de modo fenomenológico, ou seja, enquanto ainda existir uma região autenticamente viva no indivíduo.

Há sonhos que o Em Si ôntico, não está mais presente, nestes casos significa que o sujeito já atingiu uma psicologia de zumbi, não existe mais futuro, há apenas repetição mecânica na existência.

No entanto, o sonho, é sempre transparente ao mostrar se o sujeito que sonha está de modo psíquico vivo ou morto, no entanto, algumas vezes não é claro para mostrar a solução (MENEGHETTI, 2012c).

Seguem os sonhos:

- Sonho 1: "Eu lembro que assim eu estava não sei exatamente onde mas parecia um bairro lá em Salvador (BA) no centro de Salvador, o bairro do Campo Grande mas não sei exatamente o local e tinha, eu lembro que eu via meu irmão, e tinha algum tiroteio as pessoas gritando tá tento tiro, tá tendo tiro e nisso eu comecei a sentir meus dentes se esfarelando e eu passava a língua, quanto mais eu passava a língua mais caia pedaço, parecia areia e aí depois alguém tava segurando minha mão, também não sei dizer quem e aí eu lembrei meu irmão e aí eu ia queria sair pra ir contra as pessoas para ir buscar meu irmão e de repente ele vinha com o nariz sangrando e eu disse: - Meu irmão mas o que que aconteceu? E ele não conseguia falar e eu só conseguia visualizar ele assim com o nariz sangrando e meus dentes caindo”.

- Sonho 2: "Eu estava no Crossfit, mas era um lugar parecendo um labirinto feito com contêineres e comecei a subir e eu tentava descer e não conseguia até que eu acordei. Depois peguei no sono novamente e sonhei que estava em uma lancha e ela ia para o alto mar muito rápido e balançava muito e eu deitada dentro dela tentando me cobrir para não me molhar e não cair no mar, até que ela voltou para a praia e eu descia apavorada".

Em relação ao primeiro sonho, consta no prontuário Onírico (MENEGHETTI, 2012b):

Arma: Simbologia de violência mecânica anti-humana. 
Dentes: Indicam a validade do sistema defensivo (ataque e resistência), o contexto da validade dos amigos e dos parentes. Perder um ou mais dentes significa sofrer perdas no voluntarismo vital.

Sangue: Temos a experiência do sangue somente quando esse está fora da função organísmica, por isso denota ferimento ou violência física (atuada por violência externa ou por violência interior).

Neste sonho, é possível observar vários elementos de violência interna e/ou externa. Nota-se ainda, a perda do sistema defensivo, mostrando a dificuldade dela, e mesmo que diga respeito a uma situação do passado (cidade que morou com seu irmão quando fazia faculdade) ainda está ativa nela e é uma dinâmica que se atua no presente.

A pessoa de certa forma mantém uma fidelidade com aquele momento/época. As imagens, o cenário e os personagens do sonho sugerem que os acontecimentos daquela época foram assimilados com dor psíquica, onde a paciente não soube defender seu egoísmo vital e possivelmente privilegiou e estabilizou estereótipos não funcionais.

Quanto ao segundo sonho, de acordo com o prontuário Onírico (MENEGHETTI, 2012b):

Mar: É o ato infinito possível. É o todo organísmico, e as suas modalidades indicam a situação organísmica do sonhador.

Barco: Companhia ou inserção em relação feminina.

Labirinto: Símbolo do monitor de deflexão.

Academia de Ginástica (equivalente a Crossfit): Lugar ou comportamento com valores sociais ou burocráticos, sem valores vitais ou espirituais.

A parte inicial do sonho é bastante interessante, pois traz o símbolo do labirinto. A orelha interna do ser humano é constituída pela cóclea (estrutura relacionada com à audição) e pelos canais semicirculares (estrutura relacionada com o equilíbrio). Ambas estruturas têm estreita relação com o zumbido e a cóclea, principalmente, é semelhante a um labirinto. Sendo que, as duas estruturas são circulares e semelhantes a algo "sem saída".

Neste sonho, é possível observar que M. se "esconde" tem "medo" de sua potencialidade e assim não atinge sua plenitude. Observa-se também que pode apresentar dificuldades com o mundo feminino, indicando também provável déficit em lidar e usar a sua feminilidade com superioridade e inteligência. 


\subsubsection{Quanto ao Teste dos Seis Desenhos (T6D)}

O teste em questão é um instrumento psicodiagnóstico utilizado no método clínico Ontopsicológico. Esta é uma técnica não estruturada projetiva, em que se dá apenas o argumento dos deis desenhos, e o sujeito realiza de modo livre. Ele se baseia na aptidão de expor e expressar em linguagem simples.

A partir deste teste, colhe-se o prospecto geral do indivíduo em âmbito psicodinâmico e como é um teste que o próprio sujeito arquiteta mostra a sua grafia psíquica.

O teste em questão é um instrumento de grande utilidade prática, pois a partir dele pode-se ter compreensão da posição do indivíduo, o que é de suma importância para: 1) revelar a doença no sujeito; 2) compreender a sua posição complexual patológica ou infantilista; 3) evidenciar se o sujeito está aprisionado semântico, quase sempre negativo e não se dá conta. Assim como no sonho, no desenho, identifica-se a posição dinâmica, a causalidade interna do indivíduo (MENEGHETTI, 2012c).

A atividade em questão se dá do seguinte modo: são ofertadas seis folhas brancas e os seis temas fornecidos devem ser desenhados cada um sobre uma folha, seguindo uma ordem. Primeiro o desenho de uma árvore, um homem, uma mulher, a família de origem, a própria situação atual, o escopo ou situação futura. É importante que na criação seja utilizada apenas uma cor, a realização seja de uma só vez e por fim, sejam mostrados globalmente (MENEGHETTI, 2010).

Meneghetti (2012c), afirma que com este teste, pode-se notar a dinâmica que prevalece no indivíduo, que pode ser tanto de: a) estado de abertura à mudança em autorrealização (indicando bem-estar, autonomia, criatividade) ou b) estado em autossabotagem (indica frustração, estagnação e regressão).

\subsubsection{Análise do T6D}

Inicia-se com a análise qualitativa dos desenhos, como um todo eles se foram realizados com um traçado firme e contínuo, porém quanto ao espaço da folha, de modo geral, foi pouco explorado. Os desenhos não foram muito grandes e os mesmos se mantiveram, principalmente, na parte inferior esquerda. 


\subsubsection{Desenho da Árvore}

Segundo Meneghetti (2012c), o desenho da árvore diz respeito a situação psicobiológica individual, ou seja, é como ver a vida na própria vida. Esse desenho mostra a situação holística do sujeito no que diz respeito ao contexto ambiental, ele também mostra a intenção, bem como, a situação agente no indivíduo.

Figura 1 - Desenho da árvore.

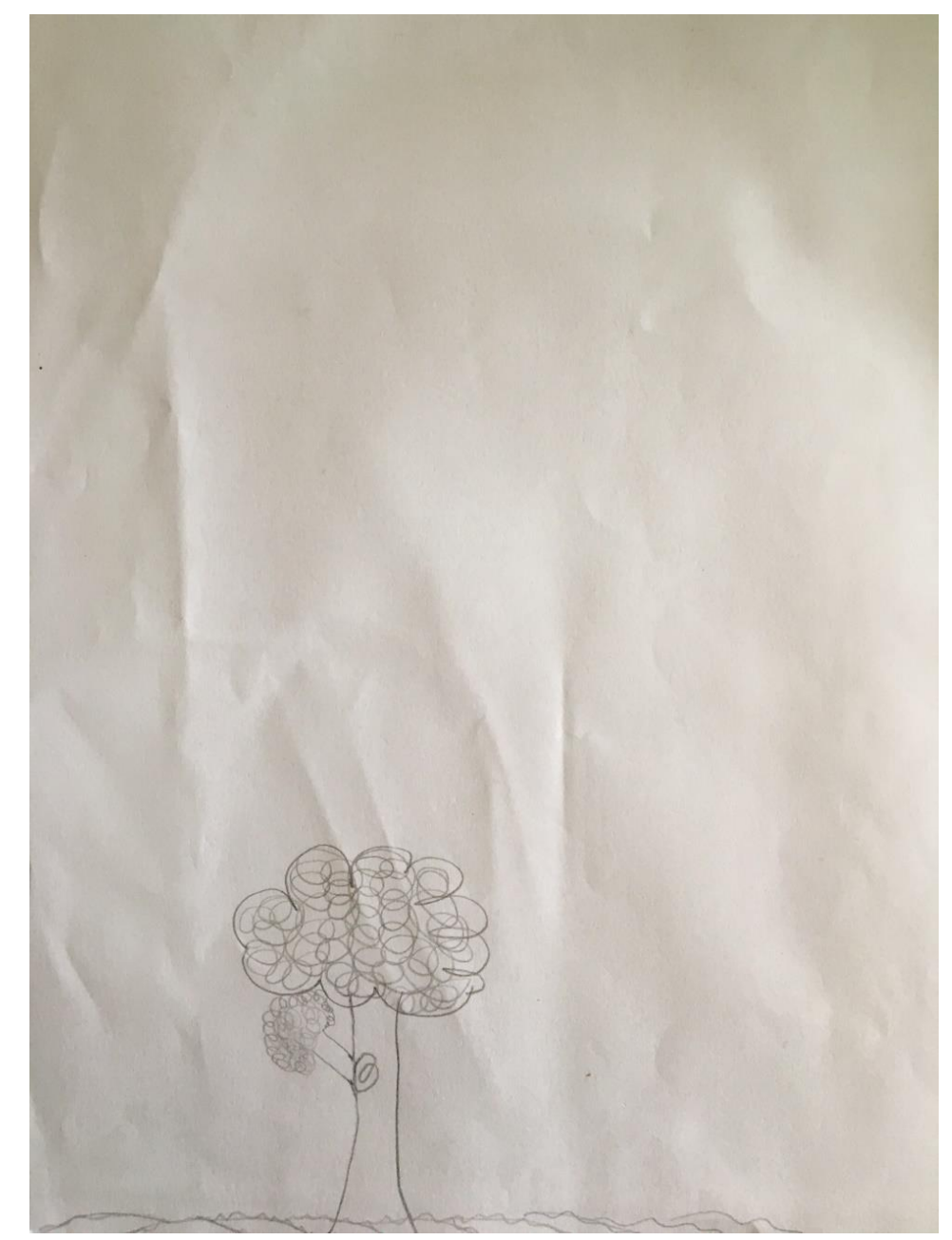

Na Figura 1 observa-se um nó e neste, está presente um galho na região medialsuperior do tronco. De acordo com Meneghetti (2012c) quando existe a presença de buracos, ramos, bem como de nós, se está diante de um complexo, ou até mesmo de uma experiência de trauma, podendo decorrer de uma doença ou violência que foi sofrida, ou ainda, de uma frustação violenta.

$\mathrm{O}$ autor contribui dizendo que o espaço que a árvore ocupa na folha indica a amplitude do desejo de ambição do indivíduo, observa-se que no caso em questão o desenho 
é pequeno em relação à folha e está inserido na parte inferior esquerda, demonstrando que neste momento a ambição não é um aspecto pulsante na vida de $\mathrm{M}$.

A copa da árvore, bem como o tronco, podem indicar a genitália masculina e feminina, assim, é importante analisar bem a impressão que se tem deles (MENEGHETTI, 2012c). No desenho em questão é possível observar um nó e neste nó está presente um galho na região medial-superior do tronco, se assemelhando a junção do órgão genital masculino com o feminino. O que pode indicar que o trauma e/ou frustração possa estar ligado com alguma questão sexual, por volta da adolescência por estar em uma região mais superior do tronco. Meneghetti (2013), afirma que a mulher que de modo contínuo faz escolhas que contradizem a lógica do Em Si ôntico, apresentam regressão no que diz respeito à sua vitalidade. A mulher que é sujeito da situação, se comporta, sem se dar conta, de modo disponível e ingênuo, mesmo que externamente não haja no aspecto sexual, não se observando mais plenitude organísmica.

O autor complementa dizendo que a mulher é sobretudo uma pessoa, uma inteligência, uma alma, e deste modo, deve investir a si mesma com uma responsabilidade superior. Deus pode esconder-se, dentro de uma mulher, o que é exclusivo para si mesmo, no entanto a mulher não sabe disso.

\subsubsection{Desenho da Mulher}

Meneghetti (2012c) relata que o desenho do mesmo sexo do desenhista traz a indicação de como ele se vê. 


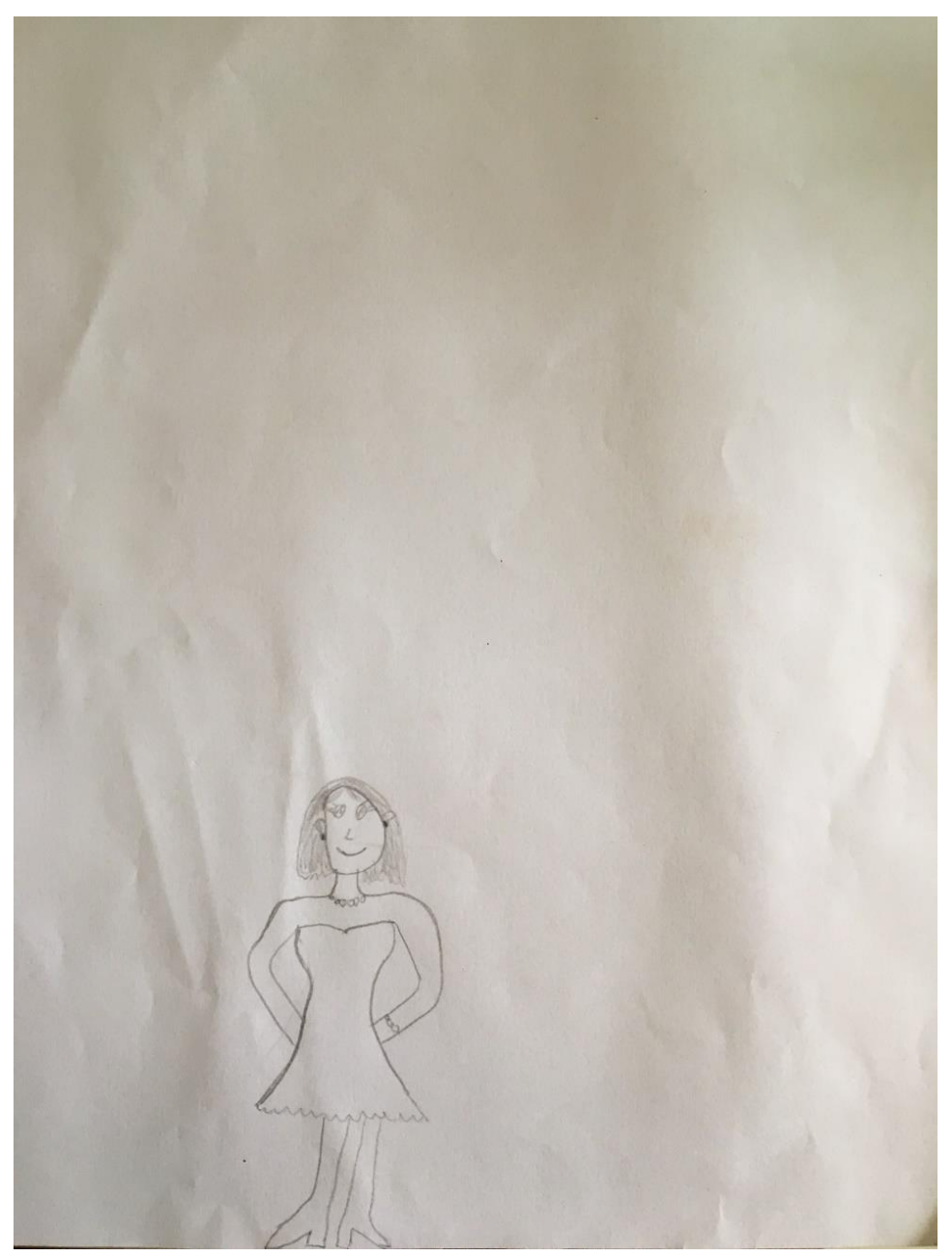

Assim como na Figura 1, na Figura 2 o espaço da folha não é explorado de modo positivo, se mostrando um desenho pequeno e na região inferior esquerda. No gráfico não se observam as mãos, o que segundo o autor, indica a falta de uma parte importante da personalidade do desenhista. Ou seja, ela não se vê grande e capaz e ainda, parece faltar/esconder parte de sua personalidade.

\subsubsection{Desenho do Homem}

O personagem do sexo oposto mostra o modo como o indivíduo visualiza o sujeito do outro sexo, bem como a maneira que se relaciona com ele. 
Figura 3 - Desenho do Homem

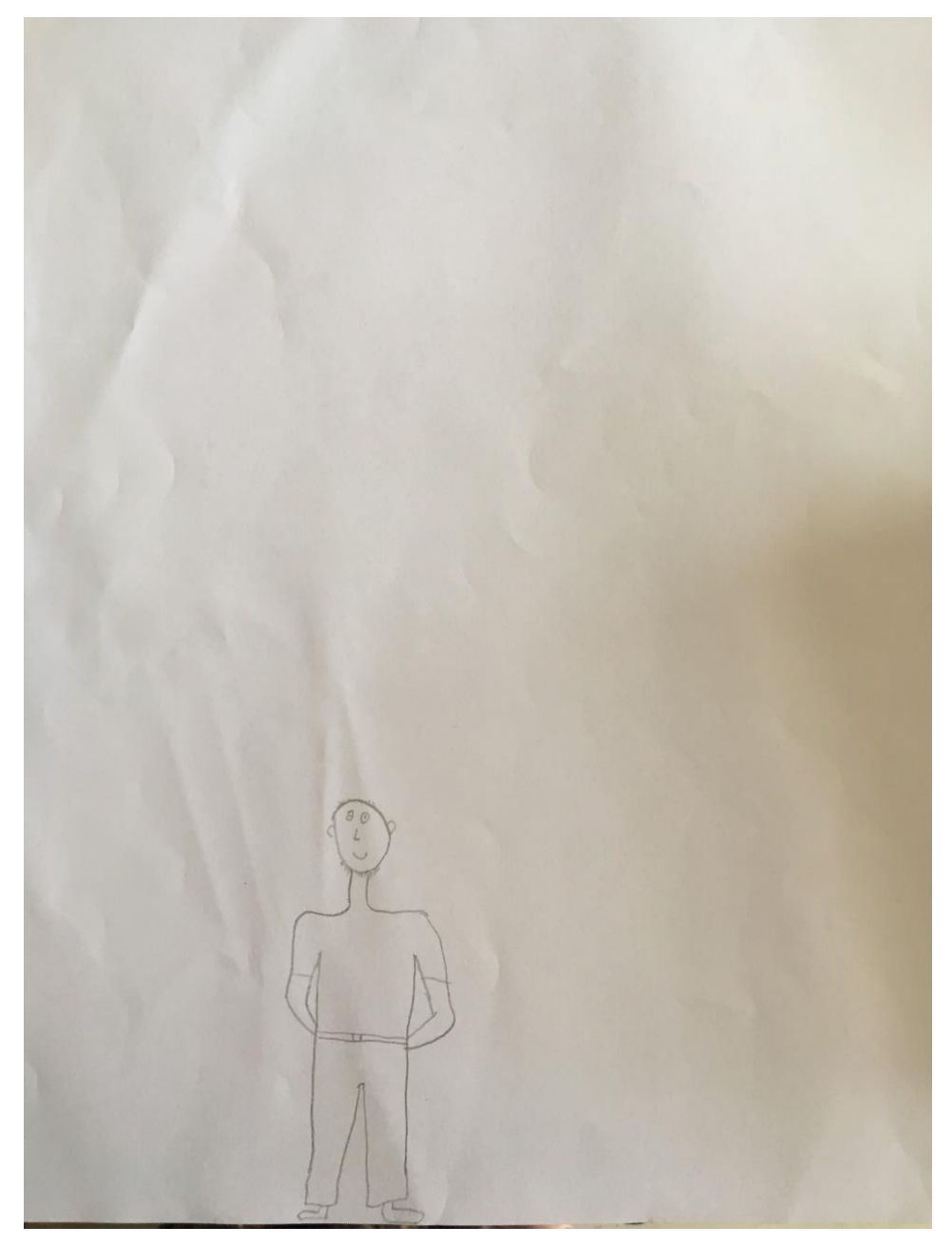

Na Figura 3 se observa semelhança com o desenho do seu irmão (Desenho da família de origem - Figura 4), podendo indicar que ele é a sua referência masculina. Neste desenho, novamente, M. o faz sem as mãos.

\subsubsection{Desenho da família de origem}

O Autor refere que neste desenho é possível identificar a dinâmica do grupo, de modo atual (exemplo: interações prevalentes, figura predominante, figura passiva e etc.) e também a posição do sujeito desenhista. 
Figura 4 - Desenho da família de origem.

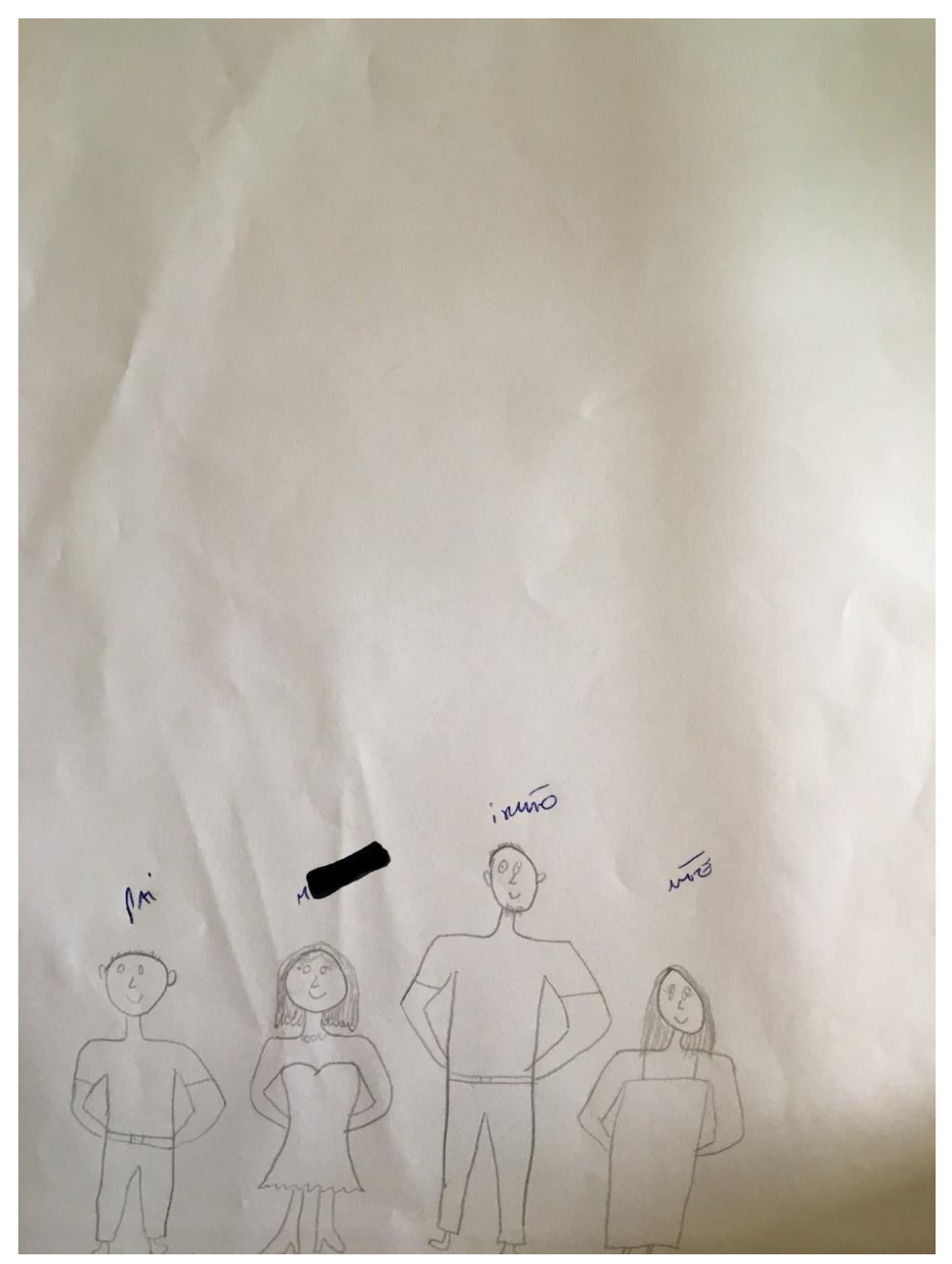

Na Figura 4 é possível verificar que todos os membros estão sem as mãos como se as escondessem, indicando faltar algo na personalidade, ou até mesmo como se tivesse algo a esconder.

A desenhista aparece entre o pai e o irmão e a mãe é desenhada na ponta, mostrando que possivelmente a relação dela seja melhor com o pai e o irmão, ou que até mesmo dispute espaço com a outra presença feminina, sua mãe.

Nota-se também que ela se desenha de modo mais feminino que sua mãe e que seu irmão é a pessoa mais evidente na família.

\subsubsection{Desenho da situação Atual}

Na Figura 5 é possível visualizar o estado, que predomina, ou seja, positivo ou negativo, que o indivíduo vive na atualidade (MENEGHETTI, 2012c). 
Figura 5 - Desenho da situação atual.

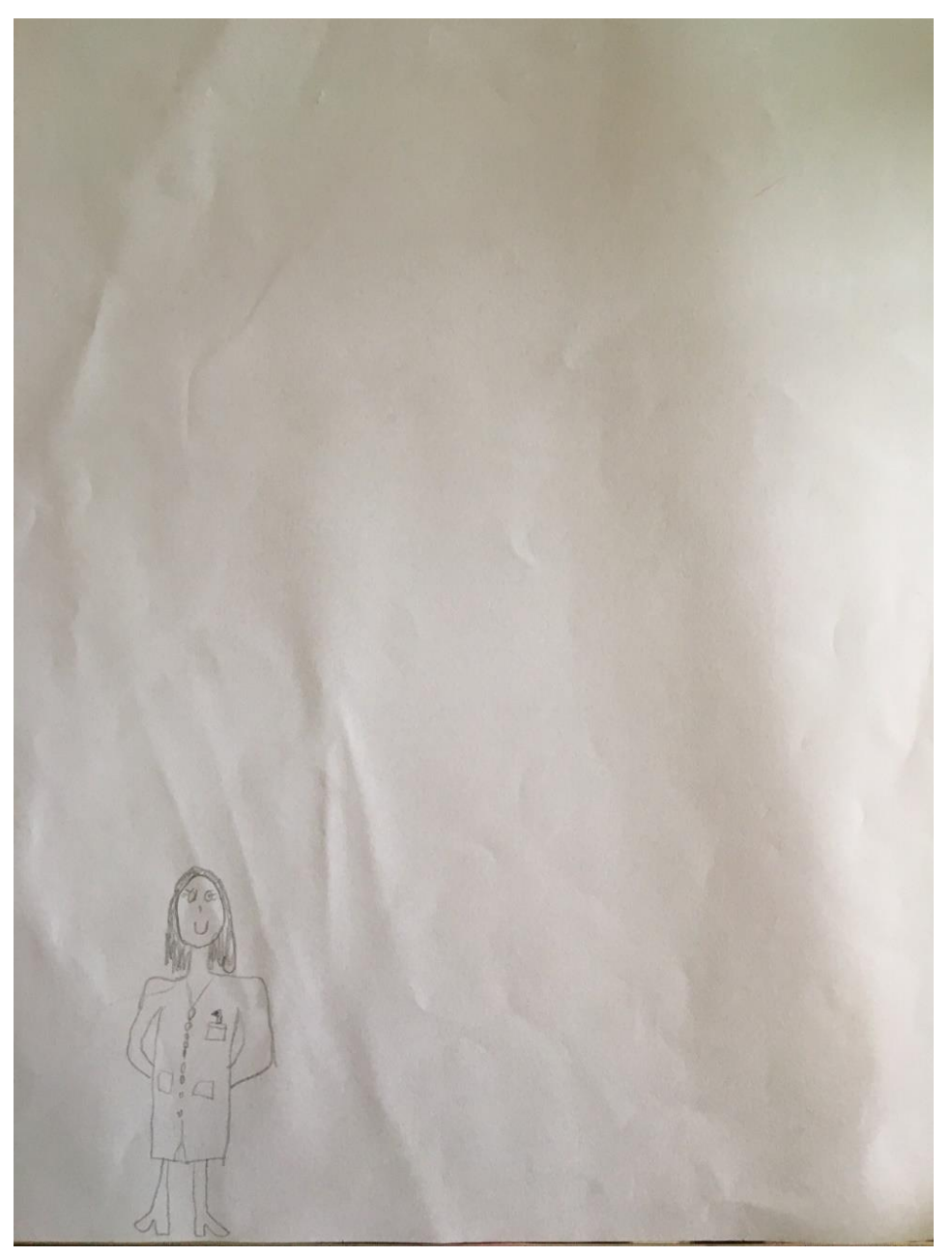

Novamente o espaço da folha é pouco explorado, desenho pequeno e no canto inferior esquerdo. As mãos estão escondidas. Embora, a desenhista se coloque com o seu jaleco habitual de trabalho, ela desenha muitos botões como se estivesse "fechada". Não se nota ambição e crescimento, nem mesmo plenitude e vigor, no desenho em questão.

\subsubsection{Desenho do escopo ou situação futura}

Esse desenho representa aspectos como: ambições, ideias ou até mesmo situações próximas que o sujeito aspira (MENEGHETTI, 2012c). 
Figura 6 - Desenho do escopo ou situação futura.

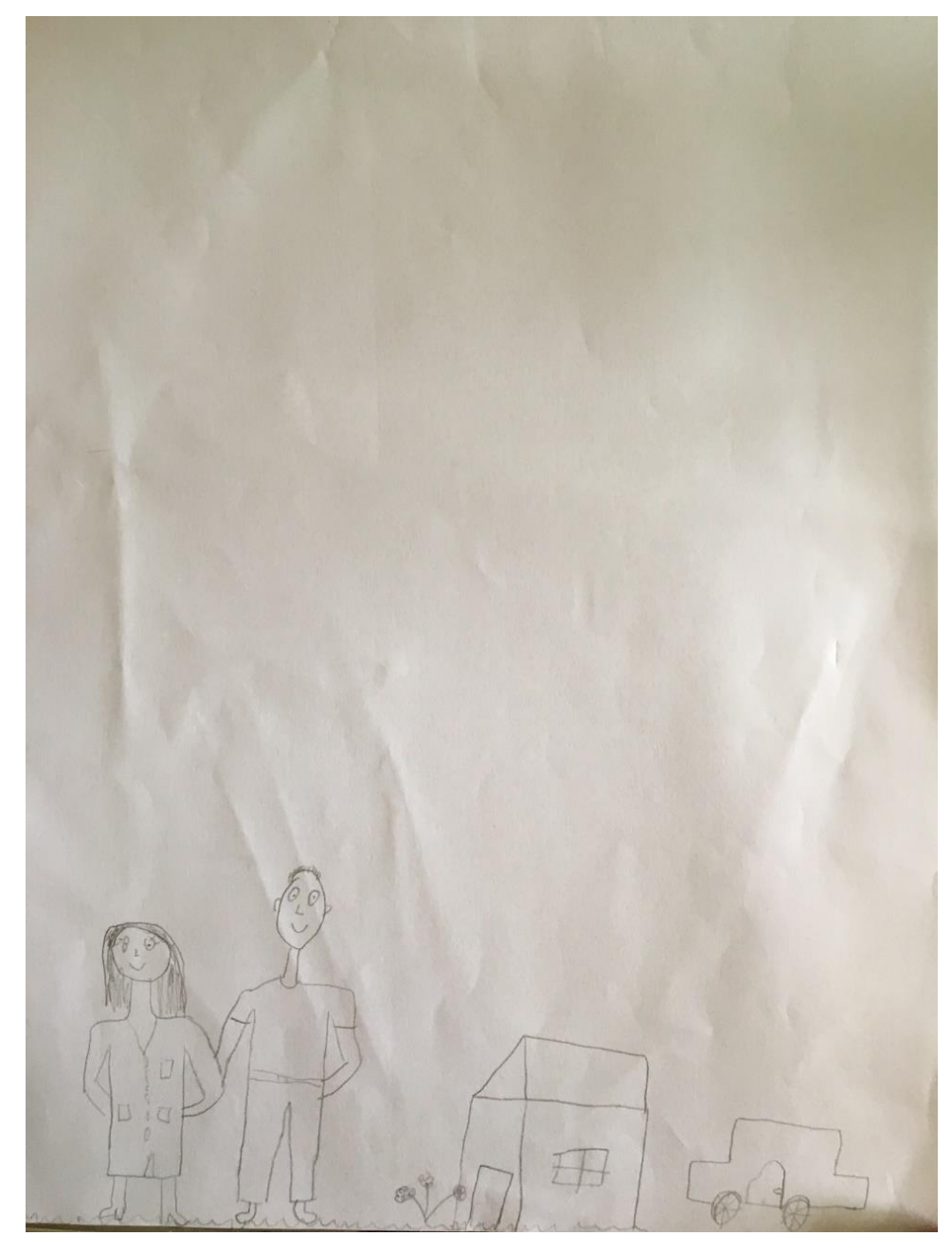

A partir do desenho de M, pode-se observar que ela fisicamente se desenha do mesmo modo que a situação atual, então no âmbito pessoal não mostra sinais de querer evoluir. Ao seu lado aparece um homem e ambos, novamente escondem as mãos. Demonstra querer bens como casa e carro, mas desenha flores que de acordo com o Prontuário Onírico representa: Flor - "Símbolo, por excelência, de promessa ou garantia do fruto, mas que na realidade não é fruto. Indica o fascínio e a atração feminina referente a um erotismo genital que de fato não acontece. Significado: falsa feminilidade e consequente efeito negativo" (MENEGHETTI, 2012b, pg. 119).

Vários dos achados até o momento indicam que M. parece não utilizar a sua feminilidade e erotismo de modo maduro e como inteligência. Acarretando erros e consequentemente frustação em sua vida. 


\subsubsection{Análise dinâmica subjetiva do T6D}

Para finalizar faz-se a análise dinâmica subjetiva do T6D, sendo os seguintes, os achados nas sete categorias (ANDREOLA, 2013):

1. Proporção entre o desenho e o espaço da folha (desenho da árvore): inadequado;

2. Posição do desenho na folha (desenho da árvore): inadequado;

3. Proporção entre o tronco, copa e base de sustentação no desenho da árvore (presença da terra em contato com a base do tronco): adequado

4. Particulares que complementam o habitat (desenho da árvore): nó e galho - inadequado;

5. Hierarquia de importância de ação na situação existencial atual (análise do desenho da situação atual comparada com o desenho da árvore): inadequado;

6. Direção de valor da ambição existencial (análise do desenho da situação futura); inadequado;

7. Intenção de empenho para o crescimento (análise do desenho de situação atual comparada com o desenho de situação futura): Inadequado

Achados estes os quais sugerem, que M., neste momento apresente Tendência a Autossabotagem, (pois não atinge o escore - cinco ou mais itens adequados- de Tendência de abertura á mudança em Autorrealização), indicando frustração, estagnação e regressão. Resultados estes, que também foram encontrados em seus sonhos.

Agora, buscando ligar todas as informações obtidas com a queixa de zumbido apresentada por M., Meneghetti (2010, pg. 399), afirma que: “o mal é a busca de um estado de homeostase em situação regressiva". O autor contribui ainda, relatando que: "A ação psíquica pode mudar as coordenadas biológicas e alterá-las molecularmente”.

A doença é um dos modos de reação que é apresentado ao sujeito, em situações que segundo ele, não existem saídas, maneiras de resolver (MENEGHETTI, 2005). A patologia é a exposição de modo mais explicito da alteração, bem como, da decadência do projeto de natureza. É o corte, o desequilíbrio, a regressão (MENEGHETTI, 2010).

Por fim, usando a definição de Sintoma presente no Dicionário de Ontopsicologia, têm-se: "Um real ou fenômeno que corre junto a um outro que é causa. Efeito de uma causa ainda não vista. Fenômeno que acompanha um acontecimento ou comportamento" (MENEGHETTI, 2012), pode-se ventilar que o sintoma do zumbido, possa estar ligado a tendência de Autossabotagem a qual compreendem: frustração, estagnação e regressão, 
apresentada por M. e que este seja um modo que o corpo demostre que a energia vital não esteja sendo utilizada em favor de crescimento e evolução.

\section{Considerações Finais}

A partir da análise dos achados foi possível observar que provavelmente M. não esteja utilizando a sua feminilidade de modo inteligente e como ponto de crescimento. Notase também, que não há sinais que a analisada esteja seguindo o seu projeto de natureza.

Detectou-se também que ela se encontra em tendência de Autossabotagem (compreendendo: frustração, estagnação e regressão). É importante ressaltar que quando o indivíduo é saudável significa há um critério de boa conduta em relação a lei da vida, deste modo, quando não há conduta adequada em relação ao projeto de natureza, bem como com as leis da vida, a doença/sintoma pode se manifestar.

Deste modo, acredita-se que o sintoma de zumbido possa ter ligação com as manifestações psíquicas demostradas pela M., pois quando o impulso de energia vital não possui mais função de ida e volta, o sujeito vivencia o mal. Principalmente, nos casos em que o sujeito deveria e tinha possibilidade de agir, não o faz. Tendo em vista que, a analisada tem considerável grau de esclarecimento, bem como visível força para atuação em sua vida, de modo positivo, em favor de crescimento.

\section{Referências}

ANDREOLA, M.T. Qualidade de vida e características de personalidade de pessoas que vivem com Aids. 2013 Dissertação (Mestrado em Ciências da Saúde) - Universidade do Sul de Santa Catarina, Tubarão, 2013.Dísponível em $:<$ https://riuni.unisul.br/bitstream/handle/12345/508/107309_Maria.pdf?sequence=1\&isAll owed=y>. Acesso em: 20 de janeiro de 2019.

LLOYD, L.L.; KAPLAN, H. Audiometric interpretation: a manual o basic audiometry. University Park Press: Baltimore, 1978. 
MEneghetTI, A. A psicossomática na Ótica Ontopsicológica. Recanto Maestro: Ontopsicologia Editrice, 2005.

MENEGHETTI, A. Manual de Ontopsicologia. Recanto Maestro: Ontopsicologia Editrice, 2010.

MENEGHETTI, A. Dicionário de Ontopsicologia. Recanto Maestro: Ontopsicologia Editrice, 2012a.

MENEGHETTI, A. Prontuário Onírico. Recanto Maestro: Ontopsicologia Editrice, 2012b.

MENEGHETTI, A. A imagem e o inconsciente. Recanto Maestro: Ontopsicologia Editrice, 2012c.

MENEGHETTI, A. Feminilidade como sexo, poder, graça. Recanto Maestro: Ontopsicologia Editrice, 2013.

SANCHEZ, T.G. Reabilitação do paciente com zumbido. In: Campos C.A, Costa H.O. Tratado de Otorrinolaringologia. São Paulo: Roca; 2002. v.2: 311-24.

SANCHEZ, T.G. Zumbido: análise crítica de uma experiência clínica e de pesquisa. 2003.Universidade de São Paulo, São Paulo, 2003.

SANCHEZ, T.G; MEDEIROS, I.R.T; LEVY, C.P.D; RAMALHO, J.R.O; BENTO. R.F. Zumbido em pacientes com audiometria normal: caracterização clínica e repercussões Rev Bras Otorrinolaringol. v.71, n.4, p.427-31, jul./ago. 2005.

SAHLEY, T.L, NODAR, R.H. Tinnitus: present and future. Curr Opin Otolaryngol Head Neck Surg. v.9, n 5, p. 323-8, 2001. 